Portland State University

PDXScholar

8-1-2017

\title{
Knowledge Spaces and the Politics of Pedagogy: Politicizing Portland State University's Environmental Education Paradigms
}

Sasha Kramer

Portland State University

Follow this and additional works at: https://pdxscholar.library.pdx.edu/honorstheses

Let us know how access to this document benefits you.

\section{Recommended Citation}

Kramer, Sasha, "Knowledge Spaces and the Politics of Pedagogy: Politicizing Portland State University's Environmental Education Paradigms" (2017). University Honors Theses. Paper 466.

https://doi.org/10.15760/honors.466

This Thesis is brought to you for free and open access. It has been accepted for inclusion in University Honors Theses by an authorized administrator of PDXScholar. Please contact us if we can make this document more accessible: pdxscholar@pdx.edu. 
Knowledge Spaces and The Politics of Pedagogy:

Politicizing Portland State University's Environmental Education Paradigms

IRB Protocol \#174170

by

Sasha Kramer

An undergraduate honors thesis submitted in partial fulfillment of the requirements for the degree of

Bachelor of Science

in

University Honors

and

Environmental Studies

Thesis Adviser

Dr. Lindsay Skog

Portland State University 


\begin{abstract}
I critically consider Portland State University’s Environmental Science and Management (ESM) department's strategies in presenting Western scientific and Indigenous knowledge in regard to environmental management and interaction through the ESM department's core curriculum. I conduct qualitative primary research through semi-structured interviews with two faculty members from the ESM department, an ESM student, and a faculty member in the Nation Studies department. The interviews illustrate the gap in the ESM's core curriculum where multicultural perspectives are not represented. My research works to understand this gap by considering the historical, political, and economic constructs for the ways in which knowledge systems of the subaltern are marginalized. Finally, this thesis prescribes the integration of Native American traditional ecological knowledge through a focused course offered in the ESM core curriculum to counter these systems.
\end{abstract}

\title{
Acknowledgment
}

I would like to dedicate my thesis paper to my father. Thank you for giving me the strength, commitment, and ability to think about and question the world around me. Your untremoring support and belief in my ability as a writer and thinker instilled the motivation I needed to finish this.

I would like to acknowledge my advisor, Lindsay Skog, and the guidance she offered me throughout this process. Thank you for challenging me. You were incredibly supportive and patient throughout this process. Thank you for introducing me to Political Ecology; you have changed the way I think about the world.

Lastly, to all of my friends and family who helped with the editing process, thank you. 


\section{Introduction}

In 1987, The World Commission on Environment and Development outlined goals situated within global institutional frameworks that set precedent to incorporate indigenous and tribal groups' local knowledge systems into global policy agreements, in regards to environment and development (United Nations, 1987). Yet, policy-makers continue to face challenges in incorporating indigenous knowledge into global agreements. For example, The United Nations Framework Convention on Climate Change (UNFCCC) is an environmental treaty that institutes an agreement across nations that sets out to combat climate change. A politics of knowledge systems plays out at the negotiation table where Western states of the Global North maintain stronger negotiating power than countries of the Global South (Gough, 2002). A funneling effect occurs where powerful industrialized states discuss and determine commitments, the ways in which climate change mitigation and adaptation will develop and how the agreement will be financed, held to and accomplished (Ibid). Gough (2002) exposes the ethical implications behind the production and dissemination of knowledge systems in the global approach to combat climate change: "If global warming is understood as a problem for all of the world's people, then we need to find ways in which all of the world's knowledge systems can jointly produce appropriate understandings and responses" (1226). Gough illustrates that at the conjunction of power and knowledge, the UNFCCC Parties with more power bolster their knowledge system, which creates an effect where those with less institutional power see their own knowledge system marginalized. A politics of knowledge systems sees those with power legitimize their own knowledge system (Western knowledge) and worldview, while disempowering and silencing other knowledge systems. The scheme laid out at the UNFCCC — constructed by intertwining systems of power and knowledge - ultimately determines the ways in which the 
world approaches climate change mitigation and adaptation. The lack of recognition of Indigenous knowledge (IK) and Traditional ecological knowledge (TEK) at the UNFCCC and its exclusion in global decision making processes is indicative of a larger omission that begins in our education system.

If western scientific knowledge is the way in which Environmental Science and Studies majors are trained to interact with the world, we must consider: Upon what culture and what set of social constructions is Western science built up in? How does the legacy of colonialism shape education in the U.S.? How have and how do western scientific knowledge systems continue to impact indigenous people? What sorts of environment/society interactions, new societies, and secret knowledge based systems are we missing out on when the knowledge systems, worldviews, and socio-environmental interactions of indigenous cultures are not discussed in the college classroom? How could studying IK and indigenous worldview inspire future environmental managers and activists to imagine new societal organizations around the ways in which we interact with the environment?

Turnbull (1997) examines the production, transmission, and utilization of Western science and contends that the production of knowledge is a social process - a social construct. Since knowledge is socially constructed, Turnbull postulates that there are "knowledge spaces," and argues that a third knowledge space must be created where Western science and marginalized knowledge systems may coexist.

Indigenous perspectives on environmental interaction and management represent a knowledge base that is in stark contrast to the dominant structures of capitalist society. This indigenous knowledge base is imbedded in a way of life that acknowledges the interconnection between ecosystems and human society. TEK contains ecological knowledge of the interaction 
between the community and its land for thousands of years (Berkes, 2012). In the academic setting, learning from TEK would not romanticize the ways of pre-colonized peoples; rather, it would acknowledge the cultural resilience of indigenous communities across the world, the ways in which they are affected by modern day society, and consider how TEK may be incorporated into future communities (Simpson, 2004a).

Thesis statement \& research questions. I center my research around two primary research questions: 1) How does the politics of knowledge systems shape the relation between Western science and Indigenous scientific knowledge systems? 2) How can Native American TEK be incorporated into environmental higher education curriculum to encourage multicultural perspectives?

I identify the political and historical background to understand the forces behind the ways in which Native American knowledge systems are rejected, marginalized and underrepresented in science education. I argue that Western scientific knowledge systems have a stronghold in education and policy because they appear to be detached from their cultural context. When deconstructed, the culture that constructs Western science becomes apparent and dominant. The fact that Western scientific knowledge stands to be detached from its cultural context is representative of Western culture. The domination of Western scientific knowledge systems paves the ways in which societies progress, solve problems and adapt; and the marginalization of indigenous knowledge systems disallows other societal forms to materialize — systems that may be more resilient and sustainable in the face of climate change.

To combat the marginalization of indigenous knowledge systems in environmental higher education at PSU, I prescribe the ethical integration of a required course within the core curriculum (offered to both Environmental Studies and Science majors) that considers Native 
American scientific knowledge systems and worldviews that are represented in Native American TEK. Through my primary and secondary research I contend that the ethical integration of a course on TEK entails that the course: 1) be taught by a Native American faculty member or be co-taught by an ESM faculty member and a Native American faculty member, with elder participation; 2) have tribal consensus; 3 ) consider the historical and political background of TEK; 4) include a portion that considers the politics of knowledge systems; 5) incorporate worldviews and knowledge production process; and 6) evade dichotomizing Western scientific knowledge systems and Indigenous scientific knowledge systems.

Case study and interviews. Using PSU's Environmental Science and Management (ESM) department as a case study, I sought to determine the prevalence of multicultural perspectives in PSU's Environmental Science and Studies core curriculum. I focused on Native American TEK because it's most relevant to PSU's campus location in Oregon, USA. Additionally, focusing on Native American knowledge systems pays respect to the sacred land that PSU's campus occupies and provides a tangible example for ESM students to examine the ways in which systems of power and knowledge marginalize Native American communities in Oregon: socially, intellectually, economically, spiritually, and in terms of loss of land and displacement.

Methods. I conducted the research for my honors thesis in the Winter quarter of the 2016 - 2017 academic year. My methodologies for data collection were qualitative and were conducted through semi-structured interviews. The study had a total of four participants: two ESM department members, one Native American Nation Studies faculty member, and one Native American ESM student. I sought out the particular ESM faculty members because they both teach courses that are offered to both Environmental Science and Studies majors through 
the respective core curricula. Also, it is in these two courses - Applied Environmental Studies II: Environmental Program Solving (ESM 221) and Introduction to Environmental Management (ESM 335) - where I saw a seamless and natural integration of multicultural perspectives, so therefore I was curious to determine the teaching strategies of these two faculty members. Additionally, I was curious about their own ideas around incorporating a course into the core curriculum on Native American TEK. The Nation Studies faculty member I interviewed taught a course on indigenous science and the environment, so I was interested to get their perspective on my thesis.

The four interviewees were selected based on their expertise about the research topic. They are not a representative sample of the ESM or Nation Studies department members.

The interviews conducted with the ESM faculty members centered around determining their specific teaching philosophies, academic and professional training, their strategies to incorporate multicultural perspectives into the core curriculum, and their thoughts and reactions in regards to incorporating a course on Native American TEK into the core curriculum.

The interview conducted with the Native American, Nation Studies faculty member organized a discussion to consider a Native American's perspective on incorporating TEK into environmental higher education. The questions within this interview were asked to determine what fears and objections, as a Native American, they have in regards to pursuing this project. Questions were asked of the participant to determine if they thought that Native American traditional ecological knowledge has a place in environmental higher education.

For the interview with the ESM Native American student, I wanted to understand their perspective on the ESM core curriculum (ESM curriculum in general) in relation to how they thought the courses and ESM faculty members integrated multicultural perspectives, but 
specifically Native American perspectives. In addition, I was curious to learn their ideas in respect to incorporating a course on Native American TEK into the ESM core curriculum — in terms of ideas for integration, their concerns and objections and the criteria they had in mind that would deliver a successful course.

\section{Literature Review}

\section{Introduction}

To understand the relationship between Western science and subaltern knowledge systems, I explore the historical framework which sheds light on how subaltern knowledge systems were first marginalized by Western systems of operation; next, I explore the politics of knowledge systems — through a postcolonial theoretical framework - to examine why Western science has a stronghold in environmental pedagogy; finally, to move towards the incorporation of Indigenous knowledge systems, I introduce the traditional ecological knowledge and worldview of the Yupiaq and natural resource management practices of the Gitga'at. Through these sequential literature reviews I surmount the relationship between Western science and TEK, Introduce Native American TEK as a viable option to dismantle that problematic relationship, which is consistent with PSU's environmental pedagogy, and showcase the power of education to alter dominant paradigms of environmental management.

\section{Enculturation Through Education}

Education was one of the first colonial institutions. Modern education interrupted the traditional education of Indian villages and stood in conflict with Native cultural systems (Kawagley, 2006). Modern public schools do not accommodate differences in worldviews; they are built to impose Western dominant culture (Berger, Berger \& Kellner, 1974). In not teaching Native school children in their own language and way of life, modern classrooms dictate that 
Native language, knowledge, and skills are of little importance (Kawagley, 2006). For a Native American, the modern academic institution instills a feeling of inferiority and forces Native students to learn values that are in conflict with their own and to learn a "better" way of seeing and doing things (Ibid.). An environmental higher education that chooses not to represent multicultural worldview contributes to this pattern and disallows Native students from learning through their own worldviews, knowledge systems and scientific practices.

The early educational system was an arm of the colonial government. It was intended to imprint colonial values and instill a docile attitude among Native communities to fulfill imperial needs (Kawagley, 2006), a process that rendered previously self-governed Native people in a state of confusion, subordination and enervation (Ibid.). Most schools were boarding schools and were deliberately placed far away from Indian villages to shift the younger generations away from their own languages, cultures, and communities (Ibid.) The boarding schools today are sites of historical trauma for Native people and still affect the Native community deeply. Maria Yellow Horse Brave Heart (2011) describes historical trauma as: "the cumulative emotional and psychological wounding over one's lifetime and from generation to generation following loss of lives, land and vital aspects of culture" (p. 3). The associated effects of historical trauma are part of the colonial legacy.

The recovery of indigenous knowledge through mainstream education allows Native students to participate in an education system that works within their own cultural worldview, values their knowledge and supports identity and cultural recovery and resilience (Simpson, 2004a). Confronting the historical impacts that Native American Nations face collectively through environmental pedagogy takes steps that lead to a realized decolonization. 


\section{On The Politics of Knowledge Systems}

The politics of knowledge systems considers the ways in which institutions of power legitimize certain systems of knowledge and knowledge production, and the implications this has in regards to societal decision making processes. Weiler (2006) argues that knowledge legitimates power; and, conversely, knowledge is legitimated by power. Knowledge and science inform societal decisions that determine environmental treaties and exist as the framework for legitimizing state power (Berger and Luckmann, 1967). Systems of knowledge and power determine the way in which we solve societal problems.

I deploy a postcolonial theoretical framework to explore the relation between Western scientific knowledge and Indigenous scientific knowledge systems. Foucault's (1987) "regime of truth" is determined by the structural forces of power that not only inform the production of knowledge but also dictate what forms of knowledge are societally produced and accepted as truths. These forces create dominant systems of organization. I will understand Foucault's conception of knowledge through Marxist post-structural theorists.

Hegemony. According to Marx, underlying economic forces determine the skeleton of a society. Historical Materialism is a Marxist methodological approach and a theory on the progression of history, which posits that the ways in which societies produce and reproduce the material means of existence and the social systems that accompany and sustain those systems, fundamentally determine the veins of society (Seligman, 1901). Marx overtly recognized that exploitation was not the sole driver of capitalism and that the ideology of the ruling class perpetuated the reinforcement and championship of capitalism (Heywood, 1994, p. 85). Gramsci is critical of Marx's strict reliance on the role of material goods in the production of historical change (Joll, 1978). Gramsci drew from Marxist theory to understand the roles of culture, 
education, and philosophy in perpetuating class divisions (Ibid.).

Gramsci's theory of "hegemony" exposes how the state and the ruling capitalist class use cultural institutions to maintain power in capitalist societies (Gramsci, 1971). For Gramsci, the hegemony of a political class meant that the class succeeded in persuading the other classes of society to accept its own moral, political, and cultural values (Joll, 1978). The pervasiveness of hegemony is in its successful implementation. Notably, Gramsci argues that education is a significant component of that persuasion. As exposed in the previous section, Native Americans throughout the United States witnessed colonization and boarding schools — an exercise of hegemony. Colonization saw the forced loss of culture, knowledge and life. Gramsci's work bestows insight in regards to how power is constituted in ideas and knowledge. It comes to fruition in a discussion that considers the politics of knowledge systems.

The concept of Subalternity from Gramsci's Prison Notebooks (1971) helps us to understand the politics that shape the relation between Western Science and TEK. Postcolonial scholars refer to the subaltern as populations who exist within the periphery of dominant hegemonic power structures of the colony, which privilege certain political and social systems as well as geographic areas (Green, 2011). Subalternity is sometimes thought of as a form of uneven development within the frame of the nation (Rothberg \& Byrd, 2002).

Native American communities are subaltern as they exercise sovereignty that is distinctly separate from the hegemonic powers of the United States. They engender identities, and cultural and spiritual practices that exist on the margins of modern day society. Indian nations embody subalternity as they exist in a state of underdevelopment, are economically deprived, struggle to maintain their social and cultural identities in the face of neoliberalism, and live on state determined marginal lands (Warrior, 2011). 
The relation between Western science \& TEK. If all formalized environmental education relies solely on the inputs of the dominant socio-cultural epistemological framework of Western science, then does environmental pedagogy not represent other ways of knowing, especially of the subaltern, and does environmental pedagogy become an arm of cultural hegemony? And if climate change is a cultural problem and requires a cultural shift for a solution, how does working in dominant frames of knowledge set the stage for change? To answer this question, I consider if and how Western scientific knowledge acts as a hegemonic tentacle itself.

Western science has its origin and finds its power in the time of Enlightenment. Western science claims its authority through its isolation from culture, in that it stands on a pedestal and appears to be divorced from culture. Bruno Latour (1999) questions the authority and reality of Western scientific knowledge and argues that it's is socially constructed. Western scientific knowledge is not merely a set of principles but rather, Western science embodies a culture within itself (Latour, 1986).

Turnbull (1997) takes the position that scientific knowledge is wholly Western and therefore latent with power relationships, that work to delegitimize other systems of knowledge. Turnbull explores how knowledge is linked to power:

when knowledge is accepted as truth and is effectively assimilated into the dominant society it must be standardized and homogenized which is achieved through social methods of organizing the production, transmission and utilization of knowledge (Turnbull, 1997, p. 553).

The acceptance of certain knowledge systems denies the possibility of others. Turnbull explains that these social processes lead to the construction of "knowledge spaces" and a third knowledge space must be created where Western science and marginalized knowledge systems can exist 
together.

Eijck and Roth (2007) point to cultural-historical activity theory (Leont'ev, 1978) and situate this as an analytical tool to view scientific knowledge systems within the universalism / multiculturalism debate among science education. It includes the physical and cultural components of reality, concerns itself with the usefulness of knowledge, and addresses the dynamic, heterogeneous and plural nature of human beings and understanding. Human-activity theory asserts that knowledge is always followed by its context and knowledge can only be understood fully when accompanied by an understanding of its context (Eijck \& Roth, 2007).

Foucault (1979) and Derrida (1978) question the validity of "truth" in society and conceptualize knowledge as a system situated in a framework mediated by power relationships that are culturally manufactured. Foucault contributes to the realm of geography and asks political ecologists what they know about the truth about environmental institutions and the discourse that is integral to the ways in which social institutions are presented. A power/knowledge approach poses questions that center around human/ecological interactions and examines how knowledge systems are produced. Power/knowledge explores how the domination of certain knowledge systems, like Western scientific knowledge, silence knowledge bases of the subaltern, and to what extent the dominance of actors who maintain Western scientific training exclude the knowledge systems of the subaltern, but also essentially exclude the subaltern by asking of them to practice in Western scientific methodology and discourse and not their own (Robbins, 2012).

A Power/knowledge analysis is instrumental in understanding the championship of Western scientific knowledge in relation to the management of environmental systems of thought, to make transparent that Western science is not impervious to neocolonial capitalist 
structures of American society, but rather embedded in those same structures.

As globalization gains traction and strengthens, Western scientific resource management spreads across the world (Robbins, 2012). But Western scientific resource management has yet to combat the depletion of resources and environmental degradation. The proliferation of conservation tactics and rise in reserve areas has been problematic for indigenous people worldwide, who witnessed a loss of agency and culture as well as their traditional land (Robbins, 2012). The next section will explore how a quintessential environmental management paradigm based on Western scientific scholarship rendered the knowledge system, way of life and access to land and practice marginalized for Native Americans.

\section{Tragedy of the commons: exploring the cultural constructs of Wester science.}

Garrett Hardin's quintessential theory, "Tragedy of the Commons" (1986), illustrates the ways in which a politics of knowledge shapes environmental curriculum in higher education. Tragedy of the Commons represents a mindset that permeates dominant natural resource paradigms and has a stronghold in the ESM core curriculum; Hardin's theory is presented in regards to fisheries management and the management of the commons in both ESM 221 and ESM 335.

Tragedy of the Commons rejects the knowledge base and ability of indigenous people, peasants and rural people to collectively manage the commons. The Western scientific knowledge base behind Hardin's theory and praxis, enforced the disintegration of Native American communities' moral economy — communal agreements based on reciprocity, trust, and expectations held between community members within traditional management systems that stabilize the particular ecosystem and regulate access to resources (Robbins, 2012).

Western resource management and reductionist science was developed in an era during which the worldview of the colonist and industrial developer dominated, which saw an affinity 
for utilitarianism and exploitation (Gadgil and Berkes, 1991). Hardin is responding to the ecological consequences of capitalist exploitation. In his will to protect the commons, Hardin theorizes that common property management is not made possible or done successfully without the intrusion of government forces or the privatization of natural resources. The solutions that Hardin presents represent the underlying conditions of a capitalist culture. Hardin's solutions are prescribed for a capitalist culture and represent the ways in which this Western scientific based management paradigm is produced.

My interview with the Nation Studies department member illuminates the knowledge base that Native American communities in the Pacific Northwest had prior to the onset of the Tragedy of the Commons management paradigm:

We talk about the structuring of rivers, the idea of large woody debris placements being effective at providing ecological habitat for aquatic species. In the Willamette valley, 150 years ago most of the valley was clear cut: logs were driven down tributaries of the Willamette through checkpoint dams as they moved them down the river. Logs in the river degraded and trenched the natural gravels in the tributaries of the Willamette. In the main stem of the Willamette itself, it became channelized, basically the floodlands were erased and it was channelized into one big reservoir, instead of the natural free-flowing river that it once was.

Then there was this idea that large woody trees were an impediment for salmon migration and that we should clear them out to create this English pristine look. That's something the tribes always knew - that wood was important to streams: it created habitat, a place for sediment to build up. In 1980 they finally realized you know, oh, wood is important for our streams and it's going to help repopulate them. It was a great group of researchers that came up with that but you know the tribes always had that knowledge. (Nation Studies Instructor)

Hardin's paper saw the development of conservation projects and the creation of state-owned forests, which lead to the relocation of indigenous people from their ancestral land. Native Americans had their own highly developed natural resource management strategies, which supported the health of rivers and watersheds but the establishment of National Forests saw the disintegration of these systems. It's important that contemporary environmental pedagogy recognize the legacy that conservation projects have and the rights that were taken away from 
Native American people. ESM faculty members hold a special position where they have the ability to dismantle systems of oppression, knowledge marginalization, and ethnocentrism.

The power of the academy. It is important to understand the position that the academic has in which they dictate to students the ways in which knowledge about the environment and how the environment should be managed - and to understand how a way of knowing was taken from the subaltern, intellectually but also physically through regimes of land grabs. Jones (1990) argues that the education system is a realm that perpetuates the subjugation of humans in a power-knowledge structured society. Scholars arguing for the deployment of local knowledge systems would argue that culture is an integral part of science (Turnbull, 1987). The genealogical approach that Foucault takes in Discipline and Punishment shows that the instruments of bureaucratic institutions, such as the school, prison or hospital, form knowledge systems that are informed by their relationship with society and they are infiltrated with the social, cultural and economic context. Foucault was always highly critical of epistemologies that presented knowledge as the product of unbound reasons: "[Foucault] argued that such epistemologies help to ensure our continued domination because they create the illusion that knowledge exists separately from power" (Jones, 1990, p. 42). Jones concedes that Foucault had trouble deploying the genealogical approach to the natural sciences, but contends that Foucault did hold that cultural hegemonic power structures infiltrate the natural sciences.

Spivak's chapter in Marxism and The Interpretation of Culture titled, "Can The Subaltern Speak?, radically surmounts: "Western intellectual production is complicit with Western international economic interests" (Spivak, 1988, p. 271). Spivak critiques poststructural intellectual Foucault and Deleuze for their failure to be uncritical of the historical position that intellectuals encompass. Spivak deals with the politics of representation and identifies historical 
sites where the subaltern (“The Subject”) must be represented by (“The Representer") in capitalist societies, where an agency to "speak, act and know for themselves" was and continues to be taken from the subaltern. Incorporating Edward Said's (1978) critique of the "other", Spivak claims that it's impossible for European intellectuals to imagine or comment on the "Power and Desire" that encompass the subjects of the subaltern (280). Since academics tend to speak for the subaltern, the academy and the intellectuals make it difficult for the subaltern to speak for themselves, concluding that the subaltern cannot speak. Spivak day dreams that once the subaltern can speak for themselves utopian politics will materialize.

Moreover, in an effort to decolonize and create a counter-hegemonic environmental higher education at PSU, Spivak's work urges the question: who should teach a course that incorporates Native American traditional ecological knowledge? (this question is addressed in the interviews and discussed in later sections of this paper)

\section{Introduction to Traditional Ecological Knowledge}

According to elders of the Yupiaq tribe on Kuskokwim River in Alaska, the word science elicits an intellectual process of: "trying to know," "trying to understand," "trying to grasp the origin of," and entails "a process of foreseeing and predicting the future" (Kawagley, 2006, p. 51). TEK to the scientific community is a knowledge system harbored by indigenous peoples, and contains knowledge that is tied specifically to the land that the community has interacted with and gleaned ecological knowledge from for thousands of years (Berkes, 2012). To Native people, TEK represents a practice, an ecological mindset and a way of life (Kawagley, 2006; Simpson, 2004). TEK is place and community-specific. The four aspects of TEK include: 1.) Local empirical knowledge 2.) Resource management systems (practices, tools, techniques) 3.) Traditional systems of management (cultural codes of use, social interactions, institutions of 
knowledge: elders, site/place-specific observation) and 4.) A worldview, which shapes an environmental perspective (Berkes, 2012).

There are differences between TEK and Western science, but they follow a similar process for acquiring knowledge: 1) the accumulation of observations, 2) development of hypothesis, and 3) the testing of hypothesis through strict methods or prolonged observation (Agrawal, 1995). The difference between Western science and TEK is that Western science unbounds itself from its local context to appear static, homogeneous, and singular knowledge while TEK ties itself to its local context (Eijck \& Roth, 2007). Indigenous knowledge is differentiated from Western scientific knowledge where indigenous knowledge systems (that include TEK) are characterized by; their embeddedness in their cultural and local context; the requirement of the incorporation of community; a lack of separation between nature and culture, and between subject and object; an attachment to the local environment; and elements of spirituality and sacredness (Banuri and Apffel Marglin, 1993). Contrastingly, Western scientific knowledge systems are distinguished by their commitment to disembeddedness; universalism; individualism; nature/culture and subject/object dichotomy; view nature as a commodity (Berkes, 2012). Additionally, indigenous knowledge is transmitted through communication and social customs, such as storytelling and oral language rather than in books and papers common in Western knowledge production (Cruikshank, 1998).

Worldview. An important aspect of TEK is the worldview that intertwined in the knowledge production processes of Indigenous communities (Berkes, 2012). Studying the worldview of subaltern communities could produce counter-hegemonic systems of environmental interaction and management. It's important that TEK not become untied from its worldview, cultural and local context because that leaves it open to exploitation and 
appropriation (Simpson, 2004a). The following section highlights the Yupiaq worldview and its relation to TEK to provide an example as to how TEK would be very welcome in environmental pedagogy. Following a consideration of worldview, I feature the management system of the Gitga'at to explore how TEK informs natural resource management systems.

Angayuqaq Oscar Kawagley, traditional Yupiaq man and academic, describes the Yupiaq tetrahedral worldview in Yupiaq Worldview: A Pathway to Ecology and Spirit (2006). The Yupiaq maintain an ecological mindset, which is governed by the grounding thought that all creatures, including humans, are created equal. To grow culturally, intellectually and ethically the Yupiaq methodologies include observations, experience, social interaction, and listening to the conversations and interrogations of the natural and spiritual worlds with the mind. The Yupiaq value sharing, not just with one another but also with the natural world, and hold sharing as a more efficient system of organization in terms of material possessions.

The second pillar of the Yupiaq tetrahedral worldview is the value placed on cooperation. It is thought that cooperation brings balance to the universe and does away with the negative effects of power and ambition. The Yupiaq ecological mindset embodies a practice that both respects the wisdom of the elders and prescribes a way of life through this offered wisdom, through close interactions with elders and the environment. The Yupiaq worldview incorporates a dynamic and infiltrated sense of sacredness, which correlates to their deep respect for nature and balance. To maintain this balance, the Yupiaq practice rituals, ceremonies, songs and dance that reinforced the belief that all nature is alive. These practices paved a path for the Yupiaq people to spiritually center themselves; reintegrate their relationship to nature; renew or gain new friendships. Learning about a community's' worldview as an ecological mindset could be transformative in fostering an ecological mindset in ESM students and it may initiate different 
ways of interacting and managing ecosystems.

TEK and traditional foods: A method for cultural resiliency. Production of knowledge for the Yupiaq is a social activity (Bielawski, 1990, p. 15). TEK encompasses a methodology that informs predictions made about the weather, plentifulness or scarcity of traditional foods and their peak locations. Indigenous communities ground their knowledge systems in the land and harness their philosophy and knowledge through sustenance and survival practices in close-knit interactions with their community and their landscape (Turner \& Clifton, 2006). Food production systems are an integral component of land-based communities TEK (Berkes, 2012; Menzies, 2006; Turner \& Clifton, 2006). Turner \& Clifton (2006) documents the TEK of the Gitga'at, an indigenous community of Hartley Bay on the north coast of British Columbia, developed through their cultural resilient practices around the procurement, processing and use of red laver seaweed (Porphyra abbottiae).

Edible seaweed is a traditional food of the Gitga'at. The Gitga'at are uniquely aware of the manifestations seaweed's life cycle (Turner \& Clifton, 2006). Through their hands-on experience with harvesting the species they gleaned knowledge about the growth and development of the different phases of the flora and its regenerative capacity (Ibid). There are various species of seaweeds on the coasts where the Gitga'at harvest and they have a system for species differentiation (Ibid.).

The Gitga' at practice of harvest is a model for sustainability and is accomplished through a systematic process. The Gitga't knowledge of the seaweed's life cycle and its patterns of propagation inform their techniques for harvest. Continually, their harvesting techniques entail a highly developed knowledge of ocean tides and weather. Seaweed needs to be picked every year to grow strong for the following year (Ibid). Seaweed is not spot-picked but rather cleaned out of 
one location and the next time harvesters start at the place where they left off; because of this system, the women harvesting don't have to go searching, they know of its precise location (Ibid). A cultural taboo in regards to seaweed harvest, which also doubles as a conservation measure, sees that Seaweed harvest is limited to time of low tides, a practice that allows for the regrowth of the plants. This taboo is emplaced so that people are not greedy (Ibid.).

The Gitga'at cultivated system for seaweed procurement is holistic in that it recognizes the interconnection between the forest and the coastal ecosystem. The seaweed camp is at the edge of a forest that hosts sitka spruce, western hemlock and western red cedar — the forest is used to produce the canoes, cabins, fuel and decorative headbands which support the seaweed procurement (Ibid.). The spoken acknowledgment of the connection between forest and seaweed harvest highlights a principle of reciprocity in which the forest system is conserved and managed for the Gitga'at to entertain their seaweed harvesting processes.

The seaweed harvest represents a cultural practice that engages all members of the Gitga'at through the various steps of the process: from procurement, processing, festivals and trade. Through changing times the seaweed harvest stands as a focal point for elders of the Gitga'at to maintain the traditional lifestyle and to continue the line of ecological awareness onto the next generation through practice (Turnery \& Clifton, 2006). The production of knowledge is a social process, but what happens when TEK leaves the community? Can TEK transcend its locality; its community; can it make ground in environmental higher education? What ethical questions surround such an endeavor?

The politics of TEK - moving towards education. Within the last two decades, interest in TEK increased (Berkes, 2012). The interest stems from the scientific academic community but also from the private sector. Leanne Simpson, Canadian Indigenous writer and academic at Trent 
University, expresses her disdain for the ways in which the scientific academic community depoliticized TEK by working with the knowledge of the people but not the people themselves. TEK is only taken into account and put into practice when TEK can neatly fit into the dominant structures of the scientific method; and it becomes a resource, not a system of knowledge (Simpson, 2004a). Simpson warns that the documentation and potential proliferation of indigenous knowledge leads itself open to exploitation. This is a common fear and runs deep among the cultural consciousness of Native American communities. It creates a climate of distrust in their interactions with scientists, anthropologists and the private sector.

Simpson warns that Indigenous Knowledge is generalized and depersonalized when documented and loses its interactive character between elder and student. Continually, it becomes void of its spirituality and its connection to the land (Simpson 2004a). Actions to commodify TEK embolden Simpson to incorporate TEK into environmental education at Trent University by taking a decolonization approach. Simpson stresses the importance of incorporating elders in pedagogy that incorporates TEK (Simpson, 2004b). Simpson contends that although bringing TEK into the public realm leaves it open to exploitation, she believes that providing an education of TEK is the only way to take strides to eliminate the possibility for exploitation and alleviates other detrimental systems, as well.

Beckford et al. (2010) make the argument that although not universal, as traditional ecological knowledge is place-based and tied directly to their locality, aboriginal environmental epistemologies encompass valuable lessons for teaching environmental management and exploring our relationship with the environment, to mainstream students in secondary and higher education. Beckford et al. contends that introducing aboriginal ecological knowledge into mainstream classrooms will address and reverse the damage that Western academic paradigms 
perpetuate.

The core curriculum. PSU's Environmental Science and Management (ESM) department offers two majors - Environmental Science \& Environmental Studies. The Environmental Studies core curriculum consists of 28 credits, which feature introductory courses to environmental science and problem solving, environmental policy and environmental management. Environmental Studies majors are required to take the following courses that fulfill the core curriculum requirements. ${ }^{1}$ Environmental Studies majors choose a topical area of their own to focus in, which includes 16 credits of upper division credits - half taken in the ESM department and half in the Geography department. ${ }^{2}$ The Environmental Studies major does offer a focus in the cultural concepts associated with environmental interaction and management, through the topical area — Nature \& Cultures — but these topics are not a component of the core curriculum. The courses that an Environmental Studies major who chooses to focus in the Nature \& Cultures topical areas are: Impacts Climate Change (ESM 410) Ecosystem Restoration ESM (416) Natural Resource Economics (ESM 433) Urban Forest and Parks (ESM 465) Ecology \& Mgmt/Bioinvasion (ESM 485) Cultural Geography (GEOG 430) Urban Landscapes (GEOG 432) Sustainable Cities (GEOG 442) Resource Mgmt Topics (GEOG 445) Sense of Place (GEOG 462). The Nature \& Cultures topical area does not offer a singular course on the specific worldview and management strategies of multicultural peoples and/or indigenous peoples.

The Environmental Science core curriculum consists of 68 credits and features

\footnotetext{
${ }^{1}$ which include the following courses: Orientation to ESM (ESM 150), Intro to Environmental Science (ESM 220), Applied Environmental Studies I: problem solving (ESM 221), Applied Environmental Studies II: policy considerations (ESM 222), Environmental \& Ecological Literacy (ESM 330), Methods of Environmental Management \& Lab (ESM 333/334), Intro to Environmental Management (ESM 335), Environmental Seminar (407)

2 the topical areas to choose from are: Freshwater Resources \& Management, Forest Resources \& Management, Urban Environments, Ecology \& Conservation, Environmental Policy \& Land Use or Nature \& Cultures
} 
environmental science-specific courses. ${ }^{3}$ The Environmental Science core curriculum requires 16 credits of advanced environmental topics, which must be taken from the chosen topical area the offerings for those courses fall under the following topics: Aquatic Ecology, Forest and Landscape Ecology, Urban Environments, Climate Change and Air Quality, Environmental Policy and Resource Management.

\section{Results}

Introduction. The interviews expose a gap in ESM core curriculum, where multicultural perspectives are not incorporated into environmental interaction and management. Both ESM department members attribute this to their own training, in which they were both trained in a Western scientific knowledge base and not asked themselves through their own education to study multicultural and/or indigenous perspectives. In discussing the potential to incorporate a course on Native American TEK, with all interviewees, I quickly noticed that an inclusion of a course like this would have barriers from all directions. My interview with the Native American ESM student illustrated fears that an inclusion of multicultural perspectives, specifically Native American, could be problematic if it were not given a course of its own because the material could be undeveloped, wrongly presented or only discussed in passing, with little detail or study. My interview with the Nation Studies department revealed that there are numerous concerns about incorporating Native American TEK in environmental pedagogy and that if it were to be done its implication would have to be ethical and taught by a Native American faculty member.

Discussing science education. In describing the courses they teach — Applied Environmental Studies: Problem Solving (ESM 221) and Introduction to Natural Resource

\footnotetext{
${ }^{3}$ Orientation to ESM (ESM 150), Intro to Environmental Science (ESM 220), Applied Environmental Studies I: problem solving (ESM 221), Applied Environmental Studies II: policy considerations (ESM 222), Environmental Systems Series 1-11 (ESM 320-324), Intro to Environmental Management (ESM 335), Environmental Seminar (407), 16 credits of Advanced Environmental Topics (ESM 410-499).
} 
Management (ESM 335) — ESM instructor 1 and 2, declare that there is a lack of multicultural perspectives represented in their courses:

Prior to your email invitation, I hadn't really thought about this all that much, to be honest. We begin the course focused around three different approaches to management. They represent the dominant approaches to environmental management, currently in the United States: that's the preservation approach - parks and wilderness kind of thing, the utilitarian approach, national forests and BLM lands, and then ecosystem management.

The three pictures that are on the slide are these three old white men and that's how I learned it. But boy that sure doesn't represent much in the way of either multiculturalism or diversity. It's made me reflectively think about how we could improve that, because certainly there are other perspectives and other dimensions of thought. At least in my own teaching I don't.

(ESM 335 Instructor)

In explaining their own course, ESM 335 Instructor sketches his own teaching's exclusion of multicultural perspectives in natural resource management. The course represents dominant approaches to natural resource management in the U.S. through the three historical figures: John Muir, Gifford Pinchot, and Aldo Leopold. The course does not historicize and politicize these figures or their influence. In fact, Pinchots' National Forest environmental movement saw a loss of land and land control for Native Americans and rural people (Robbins, 2012). This is where I see a seamless tie in to Native American perspectives where the course could ask students to consider the environmental management systems alive and well prior to the interference of bureaucratic control, to explore the ways in which other cultures approach environmental problem solving. Asking questions that consider how systems of knowledge and power contributed to paradigm shifts in natural resource management, and especially tracing the movement of power through those systems, is useful in terms of thinking about both dominant and subalterns natural resource schemes. ESM 335 Instructor struggles to conceive of how they could come to a balance with incorporating multicultural perspectives and the dominant paradigms: 
So then there's this question how do you teach the multicultural and diverse perspectives and not loose the kind of fundamental paradigms that guide resource management more broadly. It's a trade off in terms of the time that I have to put into numerous other things. Those three perspectives actually do a good job in portraying the major paradigms in natural resource management, our institutions at large fall under.

How does focusing on dominant approaches to natural resource management hinder the development of other approaches? Relationships of power and knowledge inform the ways in which powerful actors approach problems solving since power and knowledge are connected by a relationship of reciprocal legitimation where knowledge legitimates power and vise versa (Weiler, 2011). The knowledge presented in ESM classes is a contributing factor to the forces that determine the systems of natural resource management that can transpire in the future. Science, presented to be devoid of its cultural context, is depoliticized and is a powerful tool that informs decision makers (Ibid.). Presenting ahistorical and apolitical dominant paradigms of natural resource management rewrites environmental history in terms of natural resource management, which marginalizes indigenous perspectives and indigenous scientific knowledge and ultimately restricts approaches to the world's most debilitating and socioeconomic problems (Corsiglia and Snively, 1997).

Next I discuss with the ESM instructors, their relationship with Western science and its underlying capacity to crowd out different perspectives:

I think there can be a bias, where: we are scientists and we believe that this is the right way to do things and that can close us off to communicating with people and to understanding how systems work. (ESM 221 Instructor)

And:

The contextual side [of knowledge] is messier and it doesn't sort of work nearly as linearly nor nearly as reductionist. I think the contextual perspective is like a spaghetti diagram. Whereas with objective science, you pull each noodle apart and examine it but then you don't have the context of how they're all fitting together, so I think as a department we may lose some sight of that just because of the nature and the makeup of who the people in the department are.

All of us in the ESM department were trained in the Western science paradigm as Western 
scientific reductionists. I don't think that there is any explicit trying to crowd out other perspectives but I think that is more that we have the blinders on, so we have a harder time seeing what's on the other side. We are how we are trained. (ESM 335 Instructor)

Continually, we discuss their take on the power that Western science harbors:

Training as a Western scientist is a long process and it all feeds into this is how you do things. I think that there is a danger to buy into that hard, from all that training. Science is powerful and we do powerful things with it. To think that that's the only approach and only way to think, is really limiting. (ESM 221 Instructor)

Although neither ESM Instructor incorporated multicultural perspective into their own teaching, let alone Native American worldview or TEK, they see a knowledge space in their respective courses to incorporate multicultural perspectives or are proponents on including a course on Native American worldview and TEK:

We're here where there is lots of indigenous culture and we're on indigenous land and we have the Native American center on campus with people who are teaching climate change from various perspectives. How can we not pay attention to that and even make it central.

(ESM 220 Instructor)

And:

Bringing in multicultural perspectives would be an interesting way to reframe our environmental management class. It's a good idea. Absolutely I think it would be great to offer a course on it, by no means does sort of my lack of major focus on it mean that I don't think we should have it (ESM 335 Instructor).

The responses of the ESM instructors showcase a gap where multicultural perspectives are left out. They epitomize the marginalization of such perspectives through the concentration on dominant paradigms of natural resource management informed by a Western scientific knowledge system. Here my perception of this gap in the ESM department's core curriculum crystallizes, where Western scientific knowledge systems associated with environmental interaction and management represent the knowledge that is offered through the Environmental Science and Studies core curriculum. Additionally, the ways in which the instructors think about how multicultural perspective could be incorporated is problematic because they reference 
opening up a space for those conversations, infiltrating multicultural perspectives into the courses that already exist, which leads me to wonder if these "conversations" would be peppered, sparse and not delved into. This concern shines true in the ESM student's observation.

\section{"But only in passing": observations of a Native American ESM student. I}

interviewed a Native American pursuing a Masters through the ESM department, who has only taken upper division ESM courses with the ESM department. They articulate their observations and contend that there is a gap, where multicultural perspectives are not incorporated and specifically not Native Americans:

I do think there's a gap where indigenous knowledge systems aren't incorporated. I will say that for the 400/500 courses, we have been asked to put together group presentations and the projects that I have been a part of, always have a tribal component. IQ: Is the tribal component required? No, the students are choosing to focus on tribe based projects - it isn't required. (ESM Student)

There is some mention of Native Americans, but never in detail:

In the forest based classes there is usually some mention that tribes have their own land. Occasionally it's brought up that tribes have their own management of some forests but usually only one or two tribes are mentioned and it's only in passing. (ESM Student)

These observations illuminate that the discussions that are happening in ESM courses are incomplete and explored outside of their cultural context. The ESM Masters students sees a value in incorporating TEK into the ESM core curriculum because they believe that it could dispel stereotypical and romanticized conceptions of Native Americans, educate future environmental managers about Native Sovereignty and empower Native students to gain traction in the sciences.

"Through tribal whims". As part of this research I wanted to understand the perspectives of the Native American community at PSU. In The following interview with a Nation Studies instructor at PSU who teaches a course on indigenous science and the 
environment, they discuss their perspective on science and the value in the Native way of scientific knowledge production:

Science is basically observing things over a long period of time and making hypotheses. Robin Kimmerer is an indigenous woman but also a plant ecologist. She goes outside of the traditional science writing to develop a flow, which I think adds a lot and incorporates some of the personal feelings that are involved with resources that I think science misses. Science gives this sterile feeling.

This comment that "science gives a sterile feeling" exemplifies the feelings that scientists develop in regards to their association with the environment; therefore, this feeling too trickles down into the interactions that Environmental Science and Studies students have in their work. Intermixing TEK into science education is thought to aid in overcoming that sterile, exploitative, controlling, domineering and detached feeling that science instills (Simpson, 2004a). The Nation Studies instructor believes that TEK would be a natural fit within the ESM curriculum:

It would be very welcome in the ESM curriculum. I think it would have to be more of a course that blends United States history, Indian policy, and also specific science. It would have to show the full story. If the class was structured right and led by the right instructor, I think that it would be very fitting. Similarly to biodiversity within ecosystems of an environment, diversity of thought is also important to make a stronger product.

In regards to actually pursuing a project to incorporate a course on Native American TEK into the ESM core curriculum, The Nation Studies department member exposes his fears, objection and foreseen barriers to incorporation. In regards to incorporation, it could be difficult and time consuming to incorporate such a class, as it would require tribal consensus and participation throughout the Oregon area "if it were to be done properly":

I think it would definitely have to be taught by an indigenous teacher. If a course was incorporated into the ESM curriculum, it would have to be done in a good way through tribal whims. [It] would involve a lot of communication and a lot of seats at the table to kind of think about of what would be right in that sense. Traditional knowledge itself, a lot of tribes believe that it shouldn't be in print at all or made available to the public so you might see some resistance on that end as well.

\section{fears: appropriation and exploitation.}


I would have some fear in regards to appropriation. Probably some of what my concern is, with appropriation, is even with Portland State there are poor relationships with tribes and the indigenous community itself, so I would be a little wary as well. Other cases have taken what they wanted and done with it what they wanted. We've been doing it for a long time, and now you want to hone in on it. What's your intention for it?

That's probably why there has been this divide in traditional education systems, tribal people have had mostly negative experience and when traditional knowledge has been put out there and advertised; the resources were exploited.

What I talk about in my course, you know the Western world wants TEK to be something they can transcribe and use to kind of supplement or support their science beliefs. That's not the intention of traditional knowledge, it's structured around a way of life. It's not meant to be honed, taken and dictated.

Conclusion. The interviews with the ESM instructors illuminate that there is a significant gap within the ESM core curriculum in regards to multicultural perspectives. Although the ESM instructors do seem open to the opportunity to open up a knowledge space where topics that I have discussed throughout this paper could be considered in a dedicated course, but there are significant barriers in terms of implementation. My interview with the Nation Studies department member exposes that there are significant barriers in regards to ethical implementation.

\section{Discussion}

\section{Multicultural Environmental Education}

Introduction. Following the interviews, I will consider the literature within the discourse community that is concerned with Multicultural Environmental Education (MEE) as a way to move forward. If a course on the knowledge systems and worldview of Native American tribes was to be incorporated into the ESM core curriculum, it is relevant to look at the lessons that can be gleaned from faculty members at different institutions who are making strides in the incorporation of multicultural and indigenous perspectives.

Moving forward. MEE attempts to infuse science teaching with indigenous frameworks for understanding the world around us, which opens up a space for indigenous people to 
articulate their worldviews for and on behalf of themselves, within science education (Eijck \& Roth, 2007). MEEM has gained traction in Alaska and Canada. The inclusion of local knowledge systems of natural resource management in science education, like TEK, decolonize science and environmental education and work to disempower eurocentrism, cultural imperialism, racism and ethnocentrism (Simpson, 2004a).

Lessons from MEE: Simpson (2004a) enforces that if the wisdom of the elders is to be taught in mainstream education then students should have to learn from the elders. She stresses the importance of not only learning TEK, but the importance in learning the process of ingesting TEK. A separation of the two could leave the knowledge system vulnerable to exploitation. Simpson argues that if education does not acknowledge, challenge and try to dismantle the structures of colonialism that pervade society then education contributes to the further entrenchment of the colonial project. In essence, if curricula does not decolonize, it colonizes.

Beckford (2010) strategizes the incorporation of Native American TEK in environmental education (not just higher) and offers lessons for educators for the ways in which TEK should and should not be infiltrated. If TEK is incorporated, indigenous perspectives should not be peppered through case studies or guest speakers but rather its incorporation should exist as a strong vein of the courses curriculum (Beckford, 2010). Educators must avoid perpetuating a dictomizing effect of Western scientific knowledge systems and indigenous knowledge systems, but rather educators should encourage their students to take on a reflective lens and explore how and why this dichotomy exists and how it can be dismantled (Ibid.) TEK could be put into conversation by educators as a way to communicate about the impacts of climate change. Environmentalists and environmental educators tend to talk about the impacts of climate change in a Western scientific framework, which can be inaccessible for students but also climate 
change skeptics, and that the lived experience of Native Americans in terms of how climate change has impacted hunting, trapping, fishing and ecosystems could be put forth as cultural evidence for the materialization of climate change (Ibid.).

Conclusion. The interviews and the lessons from MEE showcase that the inclusion of a course on TEK is messy. For MEE to dismantle systems of colonization, eurocentrism and cultural imperialism its inclusion must be ethical. An ethical incorporation means that the course: 1) have tribal consensus; 2) works with the knowledge production process and not just the knowledge system; 3) include the historical and economic context; 4) consider the political relationship between Western science and Indigenous knowledge; AND 5) be taught or at least co-taught by a Native American faculty member. These barriers to integration represent difficulties that may take time and cooperation, and may require new partnerships to be formed between the ESM department and Nation Studies department. I recommend that the ESM department work with the Nation Studies department to allow Environmental Science and Studies students to take a course in the Nation Studies department to fulfill a core curriculum requirement to streamline the process.

\section{Conclusion}

The absence of multicultural and Indigenous knowledge in the American education system is characteristic of a deeply imbedded colonial legacy. By studying local knowledge systems like TEK, students will assimilate into the processes in which TEK is learned and performed, thereby working towards overcoming an interaction with nature that is domineering, exploitive, and detached - a relationship that is characteristic of Western environment/society interactions (Simpson, 2004a). An infusion of a multicultural perspective is necessary because doing so introduces students to alternative worldviews, prepares students to interact with diverse 
communities, and challenges students to question their notions behind knowledge production and dissemination (Agyeman, 2002; Beckford et al., 2010). If indigenous knowledge was incorporated into the ESM department's core curriculum, environmental education would take steps to decolonize the structures that perpetuate knowledge inequality, which could contribute to native identity and cultural reclamation and lead to a decolonized relationship with the environment. In imagining new environmental interactions and systems of environmental organization and management, I think it's wise to turn to the communities of people who have directly interacted with the environment; people who intrinsically tie their identities to the environment; and people who construct worldview around their interaction with their landscapes. The fact that the knowledge base of indigenous people is absent in PSU's environmental core curriculum lends itself to critique and exploration for the ways in which economic, historical and factors of social organization contribute to that absence.

Environmentalists task themselves to solve the environmental crisis and in imagining new societies that interact harmoniously with the environment, the wisdom of the elders, traditional ecological knowledge and indigenous worldview could be instrumental in building those future societies. Also, an introduction to this sort of knowledge could inspire students to forge new systems of environmental interaction and management that counteract dominant paradigms, new paradigms that are necessary in the face of climate change. I would hope that an introduction to this sort of knowledge could inspire sustainable societies that encompass an engendered criteria that could see the fruition of decolonization. 


\section{References}

Chapter 4: Population and Human Resources. (1987). in Report of the World Commission on Environment and Development: Our Common Future. United Nations.

Agrawal, Arun. 1995. Indigenous and Scientific Knowledge: Some Critical Comments. Indigenous Knowledge and Development Monitor, Vol. 3(3): 3 - 6.

Agyeman, J. (2002) Culturing environmental education: From First Nation to Frustration (Guest Editorial). Canadian Journal of Education, Vol. 7(1): 5-12.

Banuri, T. and Apfel, F. M. (eds.) 1993. Who Will Save the Forests? London: United Nations University/Zed Books.

Beckford, C. Jacobs, C. Williams, N. Nahdee, R. (2010). Aboriginal Environmental Wisdom, Stewardship and Sustainability: Lessons From the Walpole Island First Nations, Ontario, Canada. The Journal of Environmental Education, Vol. 41(4): 239-248.

Berger, P. and Luckmann, T. (1967) The Social Construction of Reality: A Treatise in the Sociology of Knowledge. Garden City, NJ: Anchor Books.

Berger, P. Berger, B. and Kellner, H. (1974). The Homeless Mind: Modernization and Consciousness. New York: Vintage Books.

Berkes, F. (2012). Sacred Ecology. New York: Taylor \& Francis.

Bielawski, E. (1990). Cross-cultural Epistemology: Cultural Readaptation Through the Pursuit of Knowledge. Paper presented at the 7th Inuit Studies Conference. Fairbanks: University of Alaska-Fairbanks.

Brave Heart, M.Y.H., Chase, J., Elkins, J., \& Altschul, D.B. (2011). Historical trauma among Indigenous Peoples of the Americas: Concepts, research, and clinical considerations. Journal of Psychoactive Drugs, Vol. 43(4): 282 - 290. 
Corsiglia, J. Snively, G. (1997). Knowing home: NisGa'a traditional knowledge and wisdom improve environmental decision making. Alternative Journal, Vol. 23(3): 22 - 27.

Cruikshank, J. (1998). The social life of stories: Narrative and knowledge in the Yukon territory. Lincoln, NE: University of Nebraska Press.

Derrida, J. (1978). Structure, sign and play in the human sciences (A. Bass, Trans.). In J. Derrida (Ed.), Writing and difference (pp. 278 - 294). London: Routledge.

Eijck, M. Roth, W-M. (2007) Keeping the local local: Recalibrating the status of science and traditional ecological knowledge (TEK) in education. Science Education, Vol. 91(6): $926-947$.

Foucault, M. (1979). Truth and power. In M. Morris \& P. Patton (Eds.), Power, truth, strategy. (pp. 29 -48). Sydney: Feral Publications.

Foucault, M. (1975). Discipline and Punishment: The Birth of the Prison. New York: Vintage Books.

Gadgil M. and F. Berkes (1991). Traditional resource management systems. Resource Management and Optimization, Vol. 8: 127 - 141.

Gramsci, Antonio (1971) Selections from the Prison Notebooks of Antonio Gramsci. New York: International Publishers.

Green, M. (2011). Rethinking the subaltern and the question of censorship in Gramsci's Prison Notebooks. Postcolonial Studies, Vol. 14(4): 387 - 404.

Hardin, G. (1968). The tragedy of the commons. Science, Vol. 162(3859): 1243 - 1248.

Heywood, Andrew (1994) Political Ideas and Concepts: An Introduction. London: Macmillan. Joll, J. (1978). Antonio Gramsci. New York: The Viking Press and Penguin Books. 
Jones, R. (1990). Educational practices and scientific knowledge: A genealogical reinterpretation of emergence of physiology in post-Revolutionary France. In Foucault and Education: Disciplines and Knowledge. Stephen J. Ball (Ed.) London:

Routledge. (pp. 29 -48). Sydney: Feral Publications.

Kawagley, A. O. (2006) A Yupiaq Worldview: A Pathway to Ecology and Spirit. Second Edition. Illinois: Waveland Press, Inc.

Latour, B. Woolgar, S. (1979). Laboratory life: the construction of scientific facts. Los Angeles: Sage Publications

Latour, B. (1999). Pandora's hope: essays on the reality of science studies. Cambridge, Massachusetts: Harvard University Press.

Leont'ev, A. N. (1978). Activity, consciousness, and personality. Englewood Cliffs: Prentice-Hall.

Matthews, M. (1998). In defense of modest goals when teaching about the nature of science. Journal of Research in Science Teaching, Vol. 35: 161 - 174.

Robbins, P. (2012). Political Ecology: A critical introduction. Chichester, West Sussex; Malden, MA: John Wiley and Sons.

Rothberg, M. Byrd, J. (2011). Between subalternity and indigeneity. Interventions, Vol. 13(1): $1-12$.

Said, E. (1978). Orientalism. New York: Pantheon Books.

Seligman, Edwin R. A. (1901). The economic interpretation of history. Political Science Quarterly. 16 (4): $612-640$.

Siegel, H. (1997). Science education: Multicultural and universal. Interchange, 28, 97 - 108. Simpson, L. (2004a). Indigenous environmental education for cultural survival. Canadian 
Journal for Environmental Education, Vol. 7(1): 13 - 25.

Simpson, L. (2004b). Anticolonial strategies for the recovery and maintenance of indigenous knowledge. The American Indian Quarterly, Vol. 28(3/4): 378 - 284.

Spradley, J.P. (1980). Participant Observation. New York: Holt, Rinehart and Winston.

Spivak, G. (1988). Can the subaltern speak? In C. Nelson \& L. Grossberg (Eds.), Marxism and The Interpretation of Culture: 271-313. Urbana, IL: University of Illinois Press.

Turnbull, D. (1997). Reframing science and other local knowledge traditions. Futures, Vol. 29(6): $551-562$.

Turner, N. Clifton, H. “The Forest and the Seaweed: Gitga'at Seaweed, Traditional Ecological Knowledge, and Community Survival”. Ed. Charles R. Menzies. In Traditional Ecological Knowledge and Natural Resource Management (2006). University of Nebraska: $65-86$.

Warrior, R. (2011). The subaltern can dance, and so sometimes can the intellectual. Interventions, 13(1): $1-12$.

Weiler, H. Challenging the Orthodoxies of Knowledge: Epistemological, Structural and Political Implications for Higher Education. Guy Neave (ed.), Knowledge, Power and Dissent: Critical Perspectives on Higher Education and Research in Knowledge Society. Paris: UNESCO Publishing, 2006, 61-87 